\title{
Flock Composition and Pattern of Entry and Exit of Village Chickens in Punjab (Pakistan)
}

\author{
S. Sadef*, M.S. Khan ${ }^{1}$, M.S. Rehman ${ }^{1}$, M.N.M. Ibrahim² and A.M. Okeyo ${ }^{2}$ \\ Department of Animal Breeding and Genetics \\ University of Agriculture \\ Faisalabad, Pakistan
}

\begin{abstract}
The present study was conducted with the objectives to describe flock composition and pattern of entry and exit of village chicken through in-depth monitoring in six randomly selected villages belong to two sites in Punjab, Pakistan. Initial survey and six monitoring visits of the selected household in each village were made after fixed intervals for a year. The data collected on population size, sex and flock composition of various age groups of six chicken types/breeds. The number of birds in the flock fluctuated across visits and a large number of laying hens compared to other bird categories were observed in the flock. The causes of flock dynamics indicated diseases as the major reason for all bird groups. Sale of birds provided the source of income to the farmers. Improvement in management and veterinary care are suggested to enhance flock productivity and thereby increase family income.
\end{abstract}

Keywords: Chicken diseases, flock composition, in-depth monitoring, initial monitoring, village chicken

\section{INTRODUCTION}

Poultry production in Pakistan is an integral part of irrigated and non-irrigated agriculture production systems and is generally characterized by small flocks maintained under scavenging regimen with limited supplemented feeding, insufficient housing and poor health care. Rural chicken are composed of local unimproved breeds or mix of non-described types as a result of unplanned and uncontrolled breeding. In the absence of specified breed characteristics they are mentioned as indigenous/local chicken of the area even if they are a group of distinctive category of birds. Though indigenous chicken have important role in the socio-cultural and economic profile of the rural community by contributing towards household food security and income generation, their production potential is low. Number of studies had been carried over to increase the productivity of village chicken by overcoming the factors that limit its potential. Despite the marginal progress made in some of the rural poultry improvement programs, the expected results have not been accomplished. It is certain that village chicken production will continue as long as there are villages. Improvement can be brought by modifying various aspects of the chicken production system. Therefore, present study was planned under the project "Development and application of decision support tools to conserve and sustainably using genetic diversity in indigenous livestock \& wild relatives" for exploring knowledge about village production systems,

Department of Animal Breeding and Genetics, University of Agriculture, Faisalabad, Pakistan

International Livestock Research Institute (ILRI), P.O. Box 30709, Nairobi, Kenya

Corresponding author: sumsad2012@gmail.com 
production objectives, management practices and genetic diversity through participatory rural appraisal, household surveys and in-depth monitoring. This paper presents the chicken inventory information obtained on periodical changes in flock composition obtained through in-depth monitoring at study sites.

\section{METHODOLOGY}

Present study was conducted at two selected Districts, namely Bahawalpur (Site-I) and Faisalabad (Site-II) in Punjab province. These sites were selected on the basis of high number of livestock/poultry units and population per square $\mathrm{km}$ along with distinct agroecological characteristics. Site-I and Site-II consist of sandy desert and irrigated land, respectively. Three villages from each site were randomly selected in this study. In-depth monitoring was conducted in two phases.

\section{Initial monitoring}

In the first phase all the households were selected and data were collected for number of birds sex and age groups for six chicken breeds viz. Aseel (ASL), Fayoumi (FYM), Nakedneck (NNK), Rhode Island Red (RIR), Crossbred (Fayoumi X Rhode Island Red + Fayoumi X Rhode Island Red X Aseel + Fayoumi X Rhode Island Red X unknown + other crossbred) and Others (White Leghorn + other local Desi).

\section{In-depth monitoring}

The second phase of the survey was started after two months of the initial monitoring survey. Sampling unit for the in-depth survey were made based on the results from the initial monitoring survey and the clusters derived from the household GPS positions obtained in the baseline survey. Households were clustered using "near distance" $50 \mathrm{~m}$ radius or $100 \mathrm{~m}$ diameter. The rationale behind clustering was that birds in free range systems rarely abide to the household boundaries. One or two households were randomly selected from each cluster for in-depth monitoring survey as representative sample households. The number of households surveyed under initial in-depth is given in Table 2. Six rounds of in-depth monitoring surveys were conducted at two months intervals for one year and data was analyzed using Statistical Package for Social Sciences (SPSS, 2011).

\section{RESULTS AND DISCUSSION}

Different aspects of chicken inventory observed during in-depth monitoring for a period of one year are presented in this study. Time period of six visits in two sites is presented in Tables 1 .

\section{Chicken inventory information}

Average number of birds available with the farmer during initial monitoring visits is given in the Table 2. The average number of birds (13.5 vs 11.6) found in initial in-depth survey was higher in Site-II than Site-I while the number of households keeping chicken was higher in Site-I than Site-II. The farmers predominantly kept crossbred at both sites followed by RIR and ASL at Site-I while at Site-II crossbred were followed by ASL and other category and others (Table 3). The total number of chicken and households in longitudinal surveys 
declined from $1^{\text {st }}$ through the $6^{\text {th }}$ visit at both sites. Number of pullets and cockerels increased from $1^{\text {st }}$ to last visit while there was decrease for all other age groups at both sites (Table 4).

\section{Chicken exits from the farm}

Among the various reasons of chicken exit from farm, death due to diseases was the major cause of exit in all age classes at both sites while slaughter for home consumption was the second major reason of pullet, cock and cockerel exits at Site-I and pullet, cock, hen and cockerel at Site-II. Number of losses of birds due to predators was higher (14 vs 2) at Site-II than Site-I. Hens and pullets were reported more under attack. Exits due to sales (business and urgent money) were recorded at both sites. The number of exits due to other reasons (natural death/death due to management/sold due to old age/ gift to relative or poor) was 21 and 6, respectively at Site-I and II (Table 5).

Table 1. Time duration of initial in-depth survey and in-depth monitoring visits at two sites

\begin{tabular}{lcc}
\hline \multirow{2}{*}{ Visit No. } & \multicolumn{2}{c}{ Time of visit } \\
\cline { 2 - 3 } & Site-I & Site-II \\
\hline Initial & July/Aug-2011 & July/Aug-2011 \\
1 & Nov-2011 & Oct-2011 \\
2 & Feb-2012 & Jan-2012 \\
3 & March-2012 & March-2012 \\
4 & June-2012 & May-2012 \\
5 & Aug-2012 & July-2012 \\
6 & Nov-2012 & Sep-2012 \\
\hline
\end{tabular}

Table 2. Initial in-depth survey and average number of chicken at two sites

\begin{tabular}{|c|c|c|c|c|}
\hline Site & Village & $\begin{array}{l}\text { Number of } \\
\text { households }\end{array}$ & Number of birds & $\begin{array}{l}\text { Average number } \\
\text { of birds }\end{array}$ \\
\hline \multirow{4}{*}{ I } & I & 15 & 187 & 12.5 \\
\hline & II & 14 & 161 & 11.5 \\
\hline & III & 12 & 126 & 10.5 \\
\hline & Total & 41 & 474 & 11.6 \\
\hline \multirow{4}{*}{ II } & I & 14 & 226 & 16.1 \\
\hline & II & 9 & 113 & 12.6 \\
\hline & III & 11 & 119 & 10.8 \\
\hline & Total & 34 & 458 & 13.5 \\
\hline \multicolumn{2}{|c|}{ Overall total } & 75 & 932 & 12.4 \\
\hline
\end{tabular}

\section{Chicken entries to the farm}

The chicken entries were divided into three categories; birth (household hatched), purchased and gifts. Birth was the main type of entry for chicks and was recorded by 23 and 25 households at Site-I and II, with an average of 8.7 and 9.7 chicks per household, respectively. The average number of birds purchased was 3.7 and 9.7 at Site-I and II, respectively where three households received chicken as gifts in Site-I only (Table 6). 
Purchasing was the mode of entry for both adult birds and chicks at the two sites. Farmers intended to purchase hens and cocks mainly for breeding purposes. Most of the farmers at Site-I bought birds from traders while buying from other chicken keeper was common at Site-II. In most of the cases place of purchasing was the village market and chicken sellers at Site-I while a single observation of each purchase from farm gate and market was made at Site-II (Table 7).

Table 3. Number of households keeping different chicken breeds by visit at two sites

\begin{tabular}{|c|c|c|c|c|c|c|c|}
\hline \multicolumn{8}{|c|}{ Site-I } \\
\hline \multirow[b]{2}{*}{ Breeds $^{1}$} & \multicolumn{7}{|c|}{ Visit No. } \\
\hline & Initial & 1 & 2 & $\mathbf{3}$ & 4 & 5 & 6 \\
\hline ASL & 14 & 6 & 3 & 3 & 3 & 3 & 3 \\
\hline NNK & 11 & 5 & 3 & 3 & 1 & 0 & 0 \\
\hline FYM & 11 & 3 & 1 & 1 & 1 & 1 & 1 \\
\hline RIR & 26 & 12 & 11 & 9 & 10 & 9 & 6 \\
\hline Crossbred & 41 & 17 & 15 & 14 & 15 & 14 & 12 \\
\hline Others $^{2}$ & 11 & 5 & 5 & 5 & 5 & 5 & 4 \\
\hline \multicolumn{8}{|c|}{ Site-II } \\
\hline & \multicolumn{7}{|c|}{ Visit No. } \\
\hline Breeds $^{1}$ & Initial & 1 & 2 & 3 & 4 & 5 & 6 \\
\hline ASL & 17 & 14 & 11 & 9 & 9 & 7 & 7 \\
\hline NNK & 4 & 2 & 1 & 1 & 1 & 1 & 1 \\
\hline FYM & 7 & 6 & 3 & 2 & 2 & 1 & 1 \\
\hline RIR & 8 & 5 & 2 & 3 & 4 & 3 & 2 \\
\hline Crossbred & 31 & 22 & 17 & 17 & 17 & 16 & 15 \\
\hline Others $^{2}$ & 11 & 16 & 9 & 7 & 6 & 4 & 3 \\
\hline
\end{tabular}

Table 4. Number of birds under various age groups by visit at two sites

\begin{tabular}{clccccccc}
\hline \multirow{2}{*}{ Site } & Age & \multicolumn{7}{c}{ Visit No. } \\
\cline { 2 - 8 } & group & Initial & $\mathbf{1}$ & $\mathbf{2}$ & $\mathbf{3}$ & $\mathbf{4}$ & $\mathbf{5}$ & $\mathbf{6}$ \\
\hline \multirow{4}{*}{ I } & Chicks & 37 & 64 & 15 & 37 & 148 & 147 & 12 \\
& Pullets & 111 & 25 & 30 & 15 & 13 & 21 & 62 \\
& Cockerels & 67 & 20 & 6 & 3 & 4 & 0 & 36 \\
& Hens & 214 & 89 & 79 & 73 & 87 & 59 & 44 \\
& Cocks & 45 & 22 & 24 & 15 & 24 & 11 & 8 \\
& Total & 474 & 220 & 154 & 143 & 276 & 238 & 162 \\
\hline \multirow{4}{*}{ II } & Chicks & 103 & 96 & 75 & 174 & 132 & 102 & 36 \\
& Pullets & 59 & 17 & 2 & 2 & 5 & 3 & 21 \\
& Cockerels & 47 & 9 & 1 & 3 & 5 & 2 & 17 \\
& Hens & 208 & 140 & 76 & 70 & 69 & 48 & 44 \\
& Cocks & 41 & 21 & 10 & 14 & 14 & 12 & 10 \\
& Total & 458 & 283 & 164 & 263 & 225 & 167 & 128 \\
\hline
\end{tabular}


Table 5. Number of exit by cause and age group at two sites

\begin{tabular}{|c|c|c|c|c|c|c|c|c|c|c|c|c|}
\hline \multirow[b]{2}{*}{ 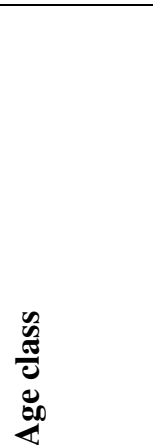 } & \multicolumn{6}{|c|}{ Site-I } & \multicolumn{6}{|c|}{ Site-II } \\
\hline & 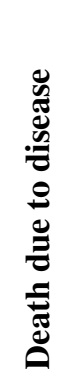 & 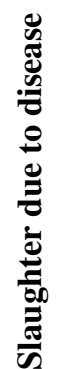 & 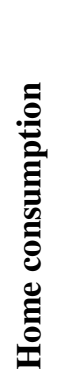 & 莞 & $\frac{0}{\pi}$ & 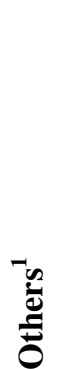 & 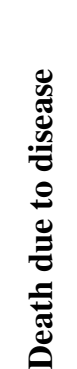 & 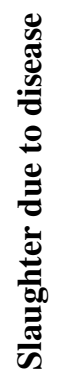 & 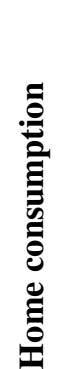 & 莞 & $\frac{\mathscr{O}}{\pi}$ & 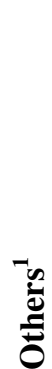 \\
\hline Chicks & 28 & 0 & 0 & 0 & 0 & 14 & 120 & 17 & 0 & 0 & 0 & 0 \\
\hline Pullets & 35 & 0 & 16 & 2 & 3 & 3 & 14 & 2 & 6 & 2 & 1 & 1 \\
\hline Cockerels & 11 & 2 & 11 & 0 & 6 & 3 & 5 & 3 & 4 & 1 & 2 & 2 \\
\hline Hens & 48 & 5 & 7 & 0 & 8 & 0 & 63 & 28 & 29 & 10 & 27 & 2 \\
\hline Cocks & 11 & 1 & 16 & 0 & 8 & 1 & 4 & 0 & 24 & 1 & 5 & 1 \\
\hline Total & 133 & 8 & 50 & 2 & 25 & 21 & 206 & 50 & 63 & 14 & 35 & 6 \\
\hline
\end{tabular}

Table 6. Sources of chicken entry at two sites

\begin{tabular}{llccc}
\hline Site & Type of entry & N & Mean & SD \\
\hline I & Birth & 23 & 8.7 & 5.30 \\
& Purchase & 22 & 3.7 & 4.63 \\
& Gift & 3 & 1.0 & 0.00 \\
\hline II & Birth & 25 & 9.7 & 7.39 \\
& Purchase & 2 & 5.5 & 6.36 \\
& Gift & --- & --- & -- \\
\hline
\end{tabular}

Table 7. Causes and sources of purchase of chicken reported by number of farmers at two sites

\begin{tabular}{llcc}
\hline $\begin{array}{l}\text { Causes and } \\
\text { sources }\end{array}$ & Site-I & Site-II \\
\hline Bought from & Other bird keeper & 2 & 2 \\
& Trader & 18 & 0 \\
& Relative & 1 & 0 \\
& Neighbor & 1 & 0 \\
\hline From where & Farm-gate & 4 & 1 \\
& Market & 10 & 1 \\
& Seller's premises & 5 & 0 \\
& Other village & 2 & 0 \\
\hline Reasons to buy & Home consumption & 2 & 1 \\
& Breeding & 5 & 1 \\
& Increase flock size & 14 & 0 \\
\hline
\end{tabular}


Chicken are the most common type of bird found among rural community. Initial visit provided an overview of the chicken population and continuous monitoring helped in observing different aspects of chicken exits and entries. The presence of birds of different breeds revealed that farmers basically kept chicken for egg production and their first preference was for crossbred birds followed by RIR at Site-I and ASL at Site-II. Tufail et al. (2012) and Farooq et al. (2002) observed the Desi (non-descript) being the most prevalent breed followed by crossbred of FYM and RIR in the province of Khyber Pakhtunkhwa (KPK), Pakistan. Desi has been described in most of the literature as non-descript; a native bird whose characteristics have not been standardized into a breed or that have been resulted as crosses of local birds with unknown. The literature did not describe the exact genetic makeup of these birds while in current study chicken population with similarities was categorized into separate groups based on visual appraisal and history. Among the existing chicken population birds of ASL, NNK, FYM, RIR and their crosses were put into separate groups. Desi considered as native bird of the area was categorized into "other local Desi" (included in others, Table 3) in the present study.

The present findings agree with those reported by Tufail et al. (2012) where higher proportion of laying hens in the flock than male birds and chicks. In majority of the indigenous chicken production systems adult to grower to chick ratio was high and this has been explained as low off take rate and low replacement caused by the high mortality of chicks and growers in the villages.

Overall, declining pattern was noticed with the number of birds kept under different age classes across the 6 visits for all breeds at both sites. Nevertheless, majority of birds kept were female while the average number of cocks in the flock was limited to less than one during majority of the visits for all breeds at both sites. Farmers kept less number of cocks in order to preserve females for brooding purposes and to increase the egg production. Chicks were home hatched while adults were mostly purchased. Birds were purchased from market or other farmers of the area with the purpose of home consumption, increase flock size and breeding. Exit was higher due to disease in all age classes specially chicks and cockerel. Cocks were slaughtered and consumed at household level in majority of the cases. Diseased hens were also slaughtered and consumed at household level. According to Mcainsh et al. (2004) male birds are rather preferred for slaughter whereas pullets are saved for reproductive purposes.

Flock size fluctuations during a year can be attributed to various intentions of a farmer. Farmers may sell or slaughter the birds at the time of onset of disease and tend to reduce the flock number during peak seasons of agricultural activities. Time between $3^{\text {rd }}$ and $4^{\text {th }}$ visit (MarchJune) was the wheat harvesting season and also hot summer, and this might be the reason of less number of birds resulted by high off take and mortality. It was also the time when grain availability was higher so number of farmers introduced new birds in the flock through purchase from market or household hatch to increase the flock at both sites. New birds entered were mostly purchased hens and cocks while chicks were hatched within the households. Dinesh et al. (2008) reported approximately similar pattern of seasonal fluctuation in chicken numbers over the year with the highest numbers in June-July, OctoberNovember and the lowest in March-April. In agreement with the present study Mogesse (2007) found variation in flock size during the year depending on the availability of feed, occurrence of diseases and presence of predators.

The major cause of chicken exit was seasonal outbreaks of disease among all age groups in current study. In agreement with present findings, Moges et al. (2010) reported 97.5\% 
household experienced chicken disease problems and Burgos et al. (2009) found one-quarter of chicks and one-fifth of grower's death within the first month of age due to disease, management, predation and theft. According to Dana et al. (2010) predators, disease and theft also account the losses from the flock. The slaughter for home consumption and sale of birds were the two other major reasons of chicken keeping and so the exit from the farm. Slaughter for home consumption especially in case of cocks and sale of birds were the second and third important reason of exit in the current study. Mengesha et al. (2008) affirmed that the main reasons of chicken keeping are for home consumption and selling. Tadelle et al. (2003) reported eggs for hatching, sale and home consumption, chick production for sale, replacement and home consumption; the preferred order of chicken keeping considered by the farmers living in Ethiopia. Present work is also in agreement with Mogesse (2007) who observed use of eggs for brooding and trade are the reasons for keeping chicken. Birds and eggs produced on farm are brought to local market and sold to traders or directly to consumers. These consumers can also be other farmers, neighbours or relative who purchases these birds to increase the flock size. Farmers may also replace exclusively with their own birds through brooding and chick production (Dinesh et al., 2008) but when they are up to purchase, they preferred adult birds. Highest births were recorded during third visit at both sites. This might be due to the moderate and suitable temperature of the month of March encouraging chick survival and broody behaviour of hens.

\section{CONCLUSIONS}

Flock dynamics showed fluctuation in number of chicken kept in all age groups throughout the year. Hens were more in number while cocks remained less than one on average among flocks at both sites. Disease is the major reason for bird exit across different age groups while entries mainly occur through household hatches and purchase from the market. Vaccination of flocks and training of farmers may overcome high mortality rates among village chickens during various seasons of the year.

\section{ACKNOWLEDGEMENT}

This study was sponsored by GEF-UNEP-ILRI FAnGR Asia Project "Development and Application of Decision Support Tools to Conserve and Sustainably Use Genetic Diversity in Indigenous Livestock \& Wild Relatives"

\section{REFERENCES}

Burgos, S. Otte, J. and Roland-Hols, D. (2009). Poultry, HPAI and livelihoods in MyanmarA Review. Mekong team working paper [online].[Accessed on 14.01.2014]. Available at www.hpai-research.net.

Dana, N. Dessie, T. Liesbeth, H. Waaij, V. Johan, A.M. and Arendonk, J.A.M. (2010). Morphological features of indigenous chicken populations of Ethiopia. pp. 11-23. Animal Genetic Resource.FAO, Rome, Italy. 
Dinesh, M.T. Geerlings, E. Solkner, J. Thea, S. Thieme, O. and Wurzinger, M. (2008). Characterization of indigenous chicken production systems in Cambodia: promoting strategies for prevention and control of HPAI. FAO, Rome, Italy.

Farooq, M. Gul, N. Chand, N. Durrani, F.R. Khurshid, A. Ahmed, J. and Asghar, A. (2002). Production performance of backyard chicken under the care of women in Charsadda, Pakistan.Livest. Res. Rural Develop., 14, 27 - 34.

Mcainsh, C.V. Kusina, J. Madsen, J. and Nyoni, O. (2004). Traditional chicken production in Zimbabwe.World's Poult. Sci. J., 60, 233 - 246.

Mengesha, M. Tamir, B. and Dessie, T. (2008).Village chicken characteristics and their seasonal production situation in Jamma District, South Wollo, Ethiopia.20 [online]. [Accessed on 30.11.2013]. Available at http://www.lrrd.org/lrrd20/8/meng20128.htm.

Moges, F. Mellesse, A. and Dessie, T. (2010).Assessment of village chicken production system and evaluation of the productive and reproductive performance of local chicken ecotype in BureDistrict, Northwest Ethiopia.Afr. J. Agric. Res., 5, 1739 - 1748.

Mogesse, H.H. (2007). Indigenous chicken populations in Northwest, Ethiopia, Ph. D. Thesis submitted to Department of Animal, Wildlife and Grassland Sciences, University of the Free State, Bloemfontein, South Africa.

SPSS Inc. Released (2011). IBM SPSS Statistics for Windows, Version 20.0: IBM Corp. Armonk, NY, USA.

Tadelle, D. Million, T. Alemu, Y. and Peters, K.J. (2003). Village chicken production systems in Ethiopia: Use patterns and performance evaluation and chicken products and socio-economic functions of chicken. Livest. Res. Rural Develop. 15 [online]. [Accessed on 30.11.2013].Available at http://www.lrrd.org/lrrd15/1/tadeb151.htm.

Tufail, M., Sajjad, M., Zulfiqar, M., Sohail, S.M. and Ahmad, I. (2012.) Economic of backyard poultry in tehsil Matta district Swat. Sarhad J. Agric., 28, 485 - 492. 